\title{
The director's words
}

Several socioeconomic and political factors have fostered mobility and intensified the capital flow from touristic activities. According to the World Tourism Organization (UNWTO), in 2008922 million tourists traveled around the world, generating a total revenue of US\$ 1.1 trillion, which corresponds to $30 \%$ of all service exports. In Brazil, the revenue generated by 4.8 million international arrivals in 2009 was of US $\$ 5.3$ billion.

These numbers reveal the astonishing proportions of tourism and thus the importance of an in-depth study of the subjects related to the different socioeconomic and political perspectives of this theme.

This special number of RAP dedicated to tourism deals with extremely relevant issues, It to the systematization of the studies in such an important area.

Sure of bringing a contribution to the systematization of such an important field of studies, $R A P$ once more steps up to the plate and promotes a privileged forum for the discussion of central themes for those professionals who are involved with management and related activities.

Enjoy your reading!

Deborah Moraes Zouain $R A P$ 's director and editor 